\title{
Neuroendocrine differentiation in prostate cancer: a mechanism of radioresistance and treatment failure
}

\author{
Chang-Deng $\mathrm{Hu}^{1}{ }^{*}$, Richard Choo ${ }^{2}$ and Jiaoti Huang ${ }^{3}$ \\ 1 Department of Medicinal Chemistry and Molecular Pharmacology, Purdue University Center for Cancer Research, Purdue University, West Lafayette, IN, USA \\ 2 Department of Radiation Oncology, Mayo Clinic, Rochester, MN, USA \\ ${ }^{3}$ Department of Pathology, David Geffen School of Medicine at UCLA, Los Angeles, CA, USA
}

Edited by:

Mercedes Salido, University of Cadiz, Spain

\section{Reviewed by:}

Simon J. Crabb, University of

Southampton, UK

Ping Mu, Memorial Sloan Kettering

Cancer Center, USA

\section{${ }^{*}$ Correspondence:}

Chang-Deng Hu, Department of Medicinal Chemistry and Molecular

Pharmacology, Purdue University College of Pharmacy, 575 Stadium Mall Dr., West Lafayette, IN 47907 , USA

e-mail: hu1@purdue.edu
Neuroendocrine differentiation (NED) in prostate cancer is a well-recognized phenotypic change by which prostate cancer cells transdifferentiate into neuroendocrine-like (NE-like) cells. NE-like cells lack the expression of androgen receptor and prostate specific antigen, and are resistant to treatments. In addition, NE-like cells secrete peptide hormones and growth factors to support the growth of surrounding tumor cells in a paracrine manner. Accumulated evidence has suggested that NED is associated with disease progression and poor prognosis. The importance of NED in prostate cancer progression and therapeutic response is further supported by the fact that therapeutic agents, including androgendeprivation therapy, chemotherapeutic agents, and radiotherapy, also induce NED. We will review the work supporting the overall hypothesis that therapy-induced NED is a mechanism of resistance to treatments, as well as discuss the relationship between therapy-induced NED and therapy-induced senescence, epithelial-to-mesenchymal transition, and cancer stem cells. Furthermore, we will use radiation-induced NED as a model to explore several NED-based targeting strategies for development of novel therapeutics. Finally, we propose future studies that will specifically address therapy-induced NED in the hope that a better treatment regimen for prostate cancer can be developed.

Keywords: neuroendocrine differentiation, prostate cancer, CREB, ATF2, radiosensitization, radiotherapy, cancer stem cell, EMT

\section{INTRODUCTION}

Prostate cancer is the second leading cause of cancer death among men in developed countries (1). In 2015, it is estimated that 27,540 men will die from prostate cancer in US according to American Cancer Society. Most of these deaths are due to the progression of localized diseases into metastatic, castration-resistant, prostate cancer (CRPC).

Based on prostate specific antigen (PSA) level, tumor grade, and the extent of primary tumor in the prostate gland, clinically localized prostate cancer is classified into low-risk (PSA $\leq 10 \mathrm{ng} / \mathrm{ml}$, Gleason score $\leq 6$, and stage T1c-T2a), intermediate-risk (PSA $>10$ but $\leq 20 \mathrm{ng} / \mathrm{ml}$, Gleason score 7, or stage T2b), and high-risk (PSA $>20$, Gleason score $\geq 8$, or stage T2c) $(2,3)$. While a majority of low-risk disease is cured with surgery or radiotherapy (RT), intermediate- and high-risk disease has a relatively high rate of recurrence following a definitive therapy. For example, approximately $30-50 \%$ of high-risk, clinically localized, prostate cancer treated with RT develop a biochemical recurrence within 5 years post-therapy, and about $20 \%$ die of prostate cancer within 10 years (4-7). Given that about $25 \%$ of patients are diagnosed with a highrisk disease at presentation (8), there has been a major effort to develop a strategy to optimally manage this group of patients in recent years.

Resistance to RT (radioresistance) can be intrinsic or acquired (9). Given the heterogeneity of prostate cancer cells, it is likely that certain cells have intrinsic radioresistance, whereas others have the ability to acquire radioresistance over the course of RT. This review discusses the recent advance in our understanding of radiation-induced neuroendocrine differentiation (NED) and the implication on RT efficacy, and proposes possible approaches to addressing radiation-induced NED.

\section{NEUROENDOCRINE DIFFERENTIATION AS A MECHANISM OF THERAPY RESISTANCE}

Normal prostate tissue consists of three types of epithelial cells: basal cells, luminal cells, and neuroendocrine (NE) cells. Unlike basal cells and luminal cells, NE cells constitute only $<1 \%$ of total epithelial cells, and their physiological role remains unclear (10). In prostate adenocarcinoma, the presence of an increased number of neuroendocrine-like (NE-like) cells is observed (10-14). It has been hypothesized that these NE-like cells may arise from luminaltype prostate cancer cells by a NED or transdifferentiation process (15-17). NE-like cells do not proliferate, and lack the expression of androgen receptor (AR) and PSA.

Clinical observations have suggested that NED correlates with disease progression and poor prognosis (14, 16, 18-28). Several mechanisms may account for the impact of NED on prostate cancer progression and therapeutic responses. First, NE-like cells do not proliferate, and thus they function as a dormant phenotype making NE-like cells particularly resistant to therapies. Second, NE-like cells express high levels of survival genes such as survivin and Bcl-2 (29-31), or exhibit alteration in calcium homeostasis 
(32), again conferring resistance to treatments. Third, NE-like cells secrete a number of peptide hormones and growth factors to support the growth of surrounding tumor cells in a paracrine manner. Lastly, NED is a reversible process $(33,34)$. For example, treatment of LNCaP cells with cAMP or cAMP-inducing agents induces NED within a few days (33). Interestingly, removal of cAMP or cAMP-inducing agents results in either retraction or shedding of the neuritic processes within $10 \mathrm{~h}$. Also, within 2 days the expression of neuron specific enolsase (NSE), a biomarker of NE and NE-like cells, returns to basal levels. Similarly, NED induced by androgen depletion (e.g., charcoal-stripped fetal bovine serumcontaining medium) can be reversed by culturing cells in normal serum-containing medium. Based on these observations, there are two possible pathways by which NED can contribute to disease progression and therapy failure (Figure 1). One is that NE-like cells can survive therapeutic interventions and thus contribute to tumor recurrence if they resume proliferation post treatments. Second, the presence of NE-like cells supports the growth of surrounding tumor cells in a paracrine manner, thus conferring to disease progression.

\section{PRE-EXISTING NED VERSUS THERAPY-INDUCED NED IN PROSTATE CANCER}

\section{PRE-EXISTING NED}

Although NE-like cells in adenocarcinoma share many characteristics of normal NE cells, they also differ in some aspects. For example, NE-like cells express some luminal cell markers, whereas NE cells express some basal cell markers (15). Accumulating evidence favors the hypothesis that NE-like cells come from a transdifferentiation process of prostate cancer cells, either from hormone-naïve or CRPC (15). There are numerous stimuli and

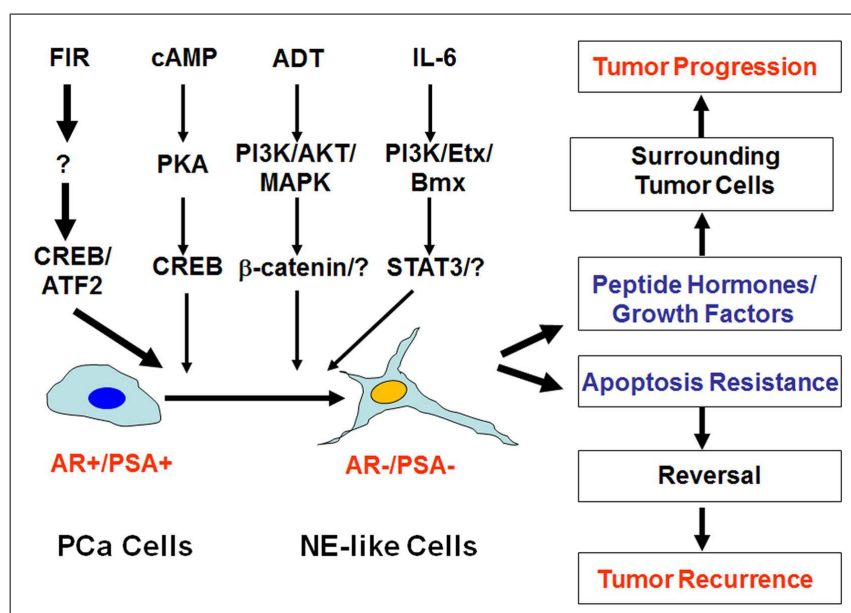

FIGURE 1 | Impact of neuroendocrine differentiation on prostate cancer progression and tumor recurrence. Neuroendocrine differentiation (NED) can be induced by fractionated ionizing radiation (FIR), CAMP, androgen-deprivation therapy (ADT), and IL-6 via distinct signaling pathways. The clinical impact of NED on prostate cancer progression and therapy response can be twofold. On the one hand, NE-like cells can produce peptide hormones and growth factors to promote tumor progression. On the other hand, the dormant and apoptosis-resistant NE-like cells may resume the ability to proliferate due to the reversibility of NED, and contribute to treatment failure and tumor recurrence. agents, which likely activate distinct signaling pathways to induce NED (15, 35). For example, cAMP signaling may activate the PKA/CREB signaling pathway to induce NED (33,36-41), whereas IL-6-induced NED appears to be mediated by activation of the PI3K/Etk/Bmx and STAT3 pathways (35, 36, 42-46) (Figure 1). Interestingly, while EGF may prevent androgen depletion-induced NED in an MAPK and PI3K/AKT-dependent manner (47), it may also promote NED in LNCaP cells in an ErbB2-dependnt manner if treated with an inhibitor of the PI3K/AKT pathway such as LY294002 $(48,49)$. Because activation of the cAMP signaling pathway and the PI3K/AKT pathways are often associated with prostate cancer development and progression, it is very likely that a subset of cells may undergo NED during prostate cancer development and progression. Thus, these NE-like cells are already present at the time of initial diagnosis of prostate cancer, and this preexisting NED confers resistance to subsequent treatments such as RT, androgen-deprivation therapy (ADT), and chemotherapy (14, $16,18-28)$.

\section{THERAPY-INDUCED NED}

Therapy-induced NED refers to acquired NED induced by a therapeutic agent. Such therapeutic agents include ADT (50-52) and docetaxel $(23,53)$. Recently, it has been shown that enzalutamide and abiraterone (two recently FDA-approved agents for the treatment of CRPC) can also induce NED and that induced NED is correlated with poor survival in CRPC patients $(54,55)$. Consistent with these clinical observations, induction of NED in prostate cancer cells by androgen depletion is well established in vitro (34, 47, 56-59) and in prostate cancer xenografts in mice (59-64). Lin et al. recently reported that a patient-derived xenograft line showed a complete induction of NED following castration (compared to no sign of NED prior to castration) (65). These observations provide convincing evidence that castration does induce NED.

\section{RT CAN ALSO INDUCE NED}

While working on the isolation of radiation-resistant sublines after a fractionated RT regimen (2 Gy/day, 5 days/week), we unexpectedly found the display of apparent neurite outgrowth by irradiated cells after a 4-week fractionated ionizing radiation (FIR) (66). Immunoblotting analysis confirmed that these cells express high levels of NE markers chromogranin A (CgA) and NSE, indicating that FIR also induces NED in vitro. Furthermore, it was observed that FIR-induced LNCaP xenograft tumors to undergo NED in nude mice, which displayed a four to fivefold increase of serum CgA after 4-week FIR (67). Consistent with this observation, in a pilot clinical study, we measured serum CgA in nine patients who were treated with RT, and found that four out of nine patients showed 1.5- to 2.2-fold increase in serum CgA after 7-week RT (67). Similarly, Lileby et al. also found that a subset of prostate cancer patients treated with RT showed elevated serum CgA levels 3 months after the treatment (21). However, these pilot clinical studies have neither addressed the issue of whether RT-induced CgA elevation correlates with RT failure nor have they established the relationship between the disease status and the extent of serum CgA elevation. Nevertheless, it is clear that NED can be induced by clinical therapeutic agents including RT 
(acquired NED), and therapy-induced NED may represent one of the mechanisms leading to treatment failure.

\section{THE RELATIONSHIP BETWEEN NE-LIKE CELLS, CANCER STEM CELLS, SENESCENT CELLS, AND EPITHELIAL-MESENCHYMAL TRANSITION}

Based on the expression of marker proteins in NE cells, luminal cells, and basal cells, it was suggested that NE-like cells arise from prostate cancer cells by a process of NED or transdifferentiation (15). However, there is also evidence suggesting that NE-like cells are derived from neural crest cells or stem cells as extensively reviewed by Conteduca et al. (17). Palapattu et al. examined the expression of cancer stem cell marker CD44 in LNCaP, DU-145, and PC-3 cells (68), and revealed that CD44 is only expressed in cells that are positive for NE markers. Consistent with this observation, the correlation between CD44 expression and NE markers (NSE and CgA) was also observed in prostate cancer tissues. Interestingly, $100 \%$ of prostatic small cell NE carcinomas, an aggressive variant of prostate cancer that is composed of highly proliferating NE cells, have CD44 expression, whereas its expression was detectable only in a minority of small cell NE carcinoma from other organs. This observation raised an interesting possibility that CD44 expression may be a useful biomarker to distinguish the origin of prostate small cell $\mathrm{NE}$ carcinoma from NE carcinoma in other organs. Because $\mathrm{CD} 44$ positive cells are capable of generating CD44 negative cells, are highly tumorigenic, and express several "stemness" genes (69), these findings support the hypothesis that CD44 positive NE-like cells are prostate cancer cell stem cells.

Recently, Kyjacova et al. used clinically relevant FIR to irradiate four human prostate cancer cell lines, and observed that there are two populations of survived cells: one is adherent, senescentlike cells, and the other is non-adherent, anoikis-resistant stem cell-like cells (70). However, since the authors did not examine the expression of NE markers, it remains unknown whether one or both populations also express NE markers. We previously isolated several sublines from irradiated LNCaP cells that lost the expression of CgA and NSE (66). All three sublines could not be induced to undergo NED by FIR. Because NED, cancer stem cells, and epithelial-mesenchymal transition (EMT) share similar properties (17), it would be interesting to examine whether these sublines exhibit properties of cancer stem cells, senescent cells, and/or mesenchymal cells. Nonetheless, these observations suggest that FIR treatment may selectively enrich the population of cancer stem cells or induce NED, senescence, and/or EMT. Several mechanisms may account for this. First, NE-like cells, cancer stem cells, and EMT or senescent cells may have the same origin (e.g., stem cells); thus, the type of phenotypic changes may depend on the type of stimuli. Second, NED, cancer stem cells, and EMT or senescence may have a significant overlap of signaling molecules that are required for the development and maintenance of each of these phenotypic changes (17). For example, expression of Snail, a major transcription factor implicated in the induction of EMT, also induces NED in LNCaP cells (71). Third, these phenotypic changes share common inducers, which could lead to induction of NED, stemness, EMT, or senescence. In fact, stress signaling, such as hypoxia, can induce both NED (72) and EMT (73), as well as enrich the cancer stem cell subpopulation (74). Finally, considering cell heterogeneity, the cellular populations may consist of all of these cell types that are induced by distinct stimuli. Future cell lineage analysis and single cell analysis will likely provide insight into the origin of NE-like cells and their relationship with other cell types.

\section{MECHANISIM OF RADIATION-INDUCED NED}

To study how NED is regulated at the transcriptional level, we examined the subcellular localization of ATF2 and observed increased cytoplasmic localization (66). ATF2 is a member of activator protein 1 (AP-1) family of proteins $(75,76)$. We discovered that ATF2 is a nucleocytoplasmic shuttling protein that possesses two nuclear import motifs and two nuclear export motifs $(77,78)$. ATF2 shuttles in LNCaP cells and IR impairs its nuclear import (66). Given that ATF2 belongs to the ATF/CREB family, and CREB is known to both regulate CgA transcription (79) and act downstream of the cAMP signaling $(20,80)$, we examined the expression and activation of CREB, and found that IR activated CREB as well as increased nuclear localization of phosphorylated CREB at Ser133 (66). These results suggest that CREB is a transcriptional activator of NED while ATF2 is a transcriptional repressor of NED, and that FIR tilts the balance between CREB and ATF2, leading to cell differentiation (Figure 2). Indeed, expression of a constitutively activated CREB is sufficient to induce NED, whereas expression of a constitutively nuclear-localized ATF2 (nATF2) can antagonize CREB-induced NED (66). Consistent with the converse roles of CREB and ATF2, nATF2, or a non-phosphorylatable CREB (CREB133A) also inhibits FIR-induced NED. Likewise, we recently established stable cell lines expressing several CREB short hairpin RNAs (shRNAs), and found that CREB knockdown significantly inhibited FIR-induced neurite outgrowth and NSE

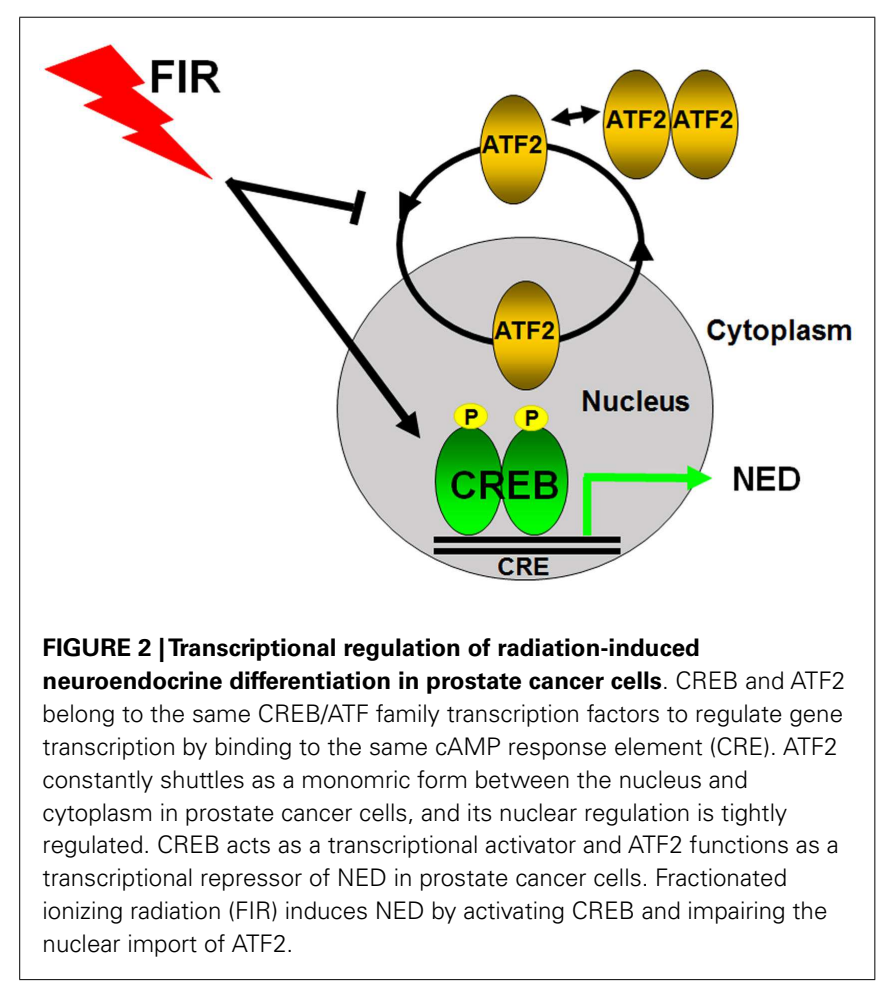


expression (81). However, CgA expression was not inhibited which was surprising given that CREB can activate CgA transcription. Because the CREB family members form different homodimers or heterodimers, the inability of CREB knockdown to inhibit CgA expression may be explained by functional compensation of other dimeric complexes. To overcome this, we established another stable cell line that has inducible expression of ACREB, a dominant negative CREB in which the basic region is replaced by acidic amino acids hence deficient in DNA-binding. This ACREB forms a dimeric complex not only with CREB but also with other CREB family members, exhibiting a potent inhibitory effect on the expression of CREB target genes $(82,83)$. Indeed, ACREB expression increased radiation-induced cell death by more than $70 \%$ in the setting of 40 Gy FIR treatment. Importantly, expression of ACREB both during the first 2 weeks (acquisition of radioresistance) and during the second 2 weeks (acquisition of NED phase) increased FIR-induced cell death (81). This result not only demonstrates the critical role of CREB in FIR-induced NED but also provides evidence that targeting either phase could be an effective approach to developing novel radiosensitizers.

\section{MULTIPLE PHASES OF RADIATION-INDUCED NED}

Fractionated ionizing radiation-induced NED differs from androgen depletion- and cAMP-induced NED in that cancer cells must survive from the treatment first. Unlike cAMP- and androgen depletion-induced NED in which almost all LNCaP cells can be induced to differentiate into NE-like cells, we observed that cell growth was largely inhibited during the first week of irradiation, and increased cell death became apparent during the second week of irradiation. However, little cell death was observed starting from the third week onward. Instead, cells began to show neurite outgrowth and cell body became smaller. With continued irradiation, cells showed extended neurite outgrowth (66). Upon 4 weeks of irradiation, almost all survived cells differentiated into NE-like cells and continued irradiation for another 3 weeks did not induce cell death. Similar processes were observed in DU-145 and PC-3 cells, though the extent of NED appears to be less than LNCaP cells (67). These observations suggest that FIR-induced NED constitutes several distinct phases: acquisition of radioresistance during the first 2 weeks, acquisition of NED during the second 2 weeks, maintenance of NED during the last 3 weeks, and reversal to the proliferating state after the completion of the FIR treatment (Figure 3).

\section{STRATEGIES TARGETING RADIATION-INDUCED NED}

A number of approaches have been attempted to target NE-like cells by either blocking secreted neuropeptide-mediated effects or inhibiting the survival signaling pathways in NE-like cells (17). However, the clinical effect of these therapeutic maneuvers remains unclear. Because NED can be induced by a variety of stimuli and therapeutic agents, the underlying molecular mechanisms of NED need to be thoroughly investigated so that targeted therapies can be developed accordingly. This is particularly important for therapy-induced NED. Further, recurrent tumors derived from therapy-induced NE-like cells may behave differently. For example, RT- and chemotherapy-induced NED involves a clonal selection, and likely reprograming of survival cells. These cells are likely cross-resistant to other treatments (66).

Using radiation-induced NED as a model, we hypothesize here that two complementary directions could be pursued to develop novel therapeutics. One is to identify targets and pathways that are specific for the acquisition of radioresistance and NED, and the other is to identify molecules that are critical for the maintenance of NE-like phenotype. In addition, developments of agents

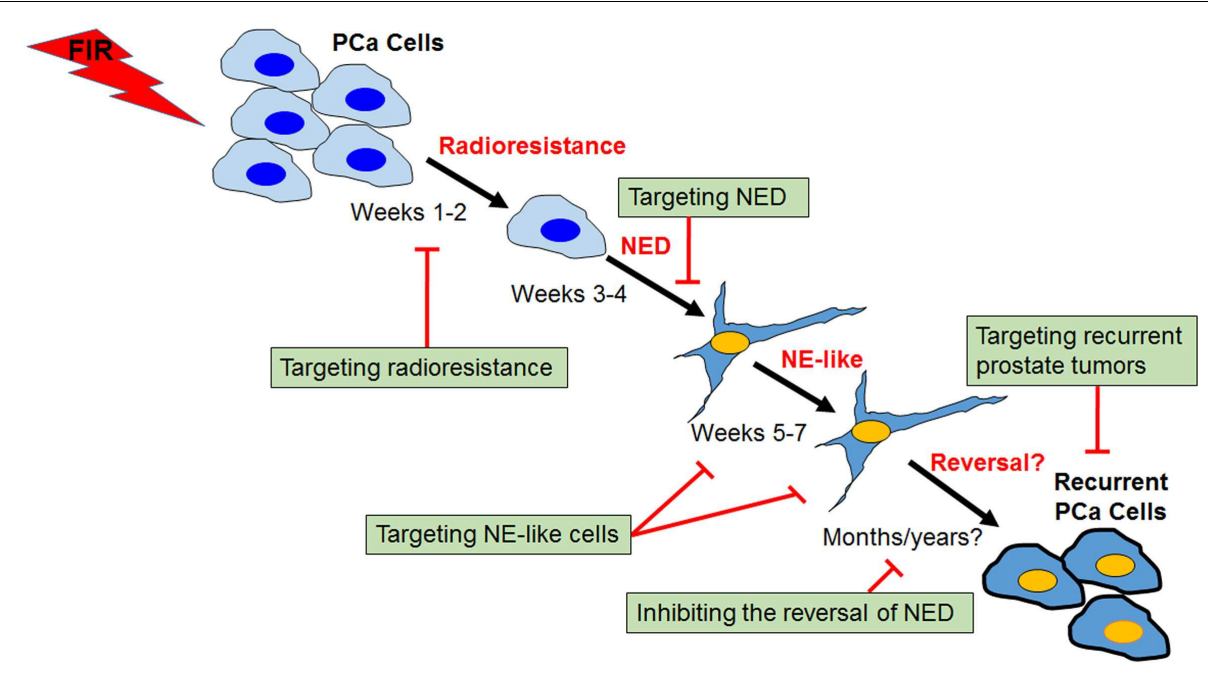

FIGURE 3 | Process and targeting strategies of radiation-induced neuroendocrine differentiation in prostate cancer cells. Shown is a schematic view of several distinct phases of fractionated ionizing radiation (FIR)-induced NED in prostate cancer cells (PCa). The critical role of CREB in the acquisition of radioresistance and NED phases has been demonstrated, and identification of upstream regulators of CREB may lead to development of novel radiosensitizers. Targeting NE-like cells and inhibiting the reversal of the "dormant" NE-like cells to a proliferating state could also be clinically useful. Further, profiling radioresistant recurrent prostate cancer cells may allow identification of molecules contributing to cross-resistance of recurrent prostate cancer after radiotherapy failure, and ultimately may lead to the development of novel therapeutic agents for the treatment of recurrent prostate tumors. 
that inhibit the reversal of NE-like cells or target recurrent tumors after RT failure should also be considered.

\section{TARGETING ACQUISITION OF RADIORESISTANCE AND DIFFERENTIATION PHASES}

Because NED can be induced by a variety of stimuli via activation of distinct mechanisms, targeting specific signaling pathways downstream of a particular inducer is a reasonable strategy. Application of such targeting agents (applied as either a single agent or a combination of multiple agents) would therefore inhibit therapy-induced NED. In the case of RT-induced NED, we have demonstrated that the CREB signaling is critical for FIR-induced NED $(66,67)$. To determine whether targeting RT-induced NED can be explored to develop a novel radiosensitizer, we established doxycycline-inducible expression system to diminish CREB activity by expressing either ACREB, a dominant negative mutant of CREB, or shRNAs to knockdown CREB. The availability of these two inducible CREB targeting approaches allowed us to specifically test whether targeting CREB during the first 2 weeks or during the second 2 weeks can sensitize prostate cancer cells to radiation. Our results showed that targeting CREB during either phase can increase FIR-induced cell death (81). This finding not only confirms that CREB is critical for FIR-induced NED but also suggests that targeting FIR-induced NED can sensitize prostate cancer cells to radiation. Since several CREB targeting agents are being developed (84), it would be interesting to test whether these agents are effective in inhibiting FIR-induced NED. Furthermore, identification of upstream regulators, e.g., protein kinases, could provide an important approach to targeting FIR-induced NED. In conclusion, this type of targeting agents can be developed as radiosensitizers by targeting either the acquisition of radioresistance, NED phase, or both phases.

\section{TARGETING NE-LIKE CELLS}

Because NE-like cells do not proliferate and rather stay as "dormant" cells, cytotoxic chemotherapeutic agents may not be effective. It is therefore necessary to understand how these "dormant" cells survive and maintain their phenotype. It is possible that an autocrine pathway confers cell survival and would be a potential target for therapeutics. Alternatively, we may target the survival pathway. For example, NE-like cells often overexpress survivin (29), and several survivin-targeting agents have been developed (85). It would be interesting to determine if targeting survivin can induce apoptosis of therapy-induced NE-like cells.

\section{INHIBITING THE REVERSAL OF NE-LIKE CELLS}

One of the potential impact of NED on tumor recurrence is its reversibility. Like cAMP- and androgen depletion-induced NED $(33,34,58)$, FIR-induced NED may also be reversible (66). The molecular mechanisms underlying this process remain unclear. However, inhibiting the reversal of NE-like cells to a proliferating state may be clinically useful if the reversibility of NE-like cells does occur in prostate cancer patients.

\section{TARGETING RECURRENT PROSTATE CANCER CELLS}

Treatment of recurrent prostate cancer remains a major challenge. A therapy for recurrent tumor is variable, and depends on the type of primary treatment. For example, a treatment strategy for recurrent prostate cancer after RT failure is different from that for recurrent prostate cancer after surgery. This is because recurrent prostate cancer after RT has undergone genetic and epigenetic changes under the selective pressures, and may be cross-resistant to other treatments. Consistent with this notion, isolated radioresistant sublines after 40 Gy of FIR are indeed cross-resistant to androgen depletion and docetaxel (66). Given that 30-50\% of high-risk and $10 \%$ of low-risk prostate cancer recur after RT, it is urgently needed to develop agents that can specifically target recurrent prostate cancer after RT failure. Because the recurrent tumor is composed of heterogeneous cells, including NE-like cells or cancer stem cells as discussed above, comparative analysis of genetic and epigenetic changes as well as signaling pathways between multiple radioresistant sublines and parental cells may lead to identification of molecular alterations that are common to all recurrent cells. If identified, molecular alterations could be validated with recurrent prostate cancer specimens, and developing novel therapeutics targeting specifically for RT-failed recurrent prostate cancer may become possible.

\section{FUTURE PERSPECTIVES \\ ANIMAL MODELS TO STUDY THE IMPACT OF NED IN PROSTATE CANCER PROGRESSION AND THERAPEUTIC RESPONSE}

The impact of NED on prostate cancer progression has been well demonstrated in vivo. It was shown that the implantation of NE mouse prostate allograft (NE-10) in nude mice bearing LNCaP xenograft tumors on the opposite flank can support the growth of LNCaP xenograft tumors under castration condition (86). This study provides compelling evidence that factors secreted by NE tumors are sufficient to support the growth of prostate tumors under castration condition (86). Consistent with this, Deeble et al. elegantly demonstrated again in castrated condition that coinjection of the constitutively activated protein kinase A subunit-induced NE-like cells and LNCaP cells into nude mice enhanced tumor growth (38). These studies corroborated in vitro findings that conditioned medium from NE-like culture can stimulate the growth of prostate cancer cells $(38,87)$, and that secreted mitogenic neuropeptides such as neurotensin are critical for the stimulation of tumor cell growth $(33,36,87)$. Interestingly, Valerie et al. also showed that treating prostate cancer cells expressing high levels of neurotensin receptor 1 (NTR1) with a selective NTR1 antagonist SR48692 sensitizes prostate cancer cells to ionizing radiation. Thus, secreted neurotensin from NE-like cells not only promotes prostate cancer cell growth but also confers the surrounding tumor cells radioresistance. Although these studies provide evidence that secreted neuropeptides and growth factors from NE-like cells in vivo can promote prostate cancer progression and alter therapeutic responses, these findings are limited to established cell lines in immunocompromised mice and thus further research must be done with a better model system.

While many genetically engineered mouse (GEM) models have been established to study the development, progression, and therapeutic responses of prostate cancer (88), a GEM model that allows for the elucidation of the impact of NED on prostate cancer progression and therapeutic response is unavailable. By transgenically overexpressing SV40 large T antigen, a TRAMP mouse model was 
established, which has a high incidence of NE tumor arising from prostate with a high potential to metastasize to lung, liver, and other tissues (89). The TRAMP mouse model is more representative of human NE carcinoma, a rare type of prostate cancer present at initial clinical presentation or in some ADT-treated setting (88). Recently, Qi et al. found that knockout of Siah2, a ubiquitin ligase, completely suppresses the development of NE tumors in the background of TRAMP (90), demonstrating a critical role of this E3 ligase in the development of NE tumors. Molecular analysis further revealed that HIF- $1 \alpha$, which is stabilized by Siah2, mediates the effect of Siah2 to selectively regulate, in combination with FoxA2, the expression of HIF target genes that are required for or involved in the development of NE tumor. Although these studies provide genetic evidence that Siah2, HIF- $1 \alpha$, and FoxA2 are required for the regulation of $\mathrm{NE}$ tumor development at the transcription level, the TRAMP mouse model does not permit the analysis of the impact of pre-existing and therapy-induced focal NED on disease progression and therapeutic response. Given that castration-induced NED also occurs in other GEM models (91, 92), it would be interesting to test if FIR also induces NED in these GEM models. Further, innovative approaches (e.g., inducible NED mouse models, chemical probes) that allow manipulation of NElike cells or NED in these GEM models will likely facilitate the study of NED impact on prostate cancer progression and radiation response. As castration-induced NED has also been reported in patient-derived xenograft model system (65), infecting the cells with lentiviruses (that can inducibly destroy NE-like cells during the course of FIR treatment) will similarly permit the study of acquired NED in radio-responsiveness.

\section{CLINICAL DIAGNOSIS OF NED IN PROSTATE CANCER PATIENTS}

Traditionally, the proteins such as CgA, NSE, synaptophin, and others that are expressed by NE-like and NE cells are used as biomarkers to identify NE-like or NE cells in tissue specimens using immunohistochemistry. However, analysis is often confounded by various factors including a sampling issue, leading to conflicting outcomes. Thus, it is generally felt that immunohistochemical analysis may not accurately represent the status of NED in a given patient. To overcome this, serum biomarkers have been used and their correlation to NED in tissues have been examined. It was found that $\mathrm{CgA}$ is the best biomarker to reflect NED in tissue (93). To date, serum CgA has been used to monitor ADT-induced NED and chemotherapy-induced $\operatorname{NED}(23,24,27,53-55,94,95)$. We and others have also observed serum CgA elevation in some patients who were treated with $\mathrm{RT}(21,67)$. Because prostate cancer cells express a basal level of $\mathrm{CgA}$, and activation of transcription factors (e.g., CREB) may also lead to increased synthesis of CgA, measurement of individual biomarkers may not accurately reflect the status of NED in tissues. In addition, obtaining a biopsy for the examination of NED in cancer tissues in post-RT setting is very challenging. Thus, it is very desirable to develop new methods that can reliably diagnose NED in cancer tissues. One approach is to test whether circulating tumor cells can be used to monitor NED in patients in addition to serum CgA measurement. Alternatively, measurement of multiple biomarkers may be necessary for a more accurate diagnosis. One example is the ratio of CgA/PSA. Measurement of serum CgA in irradiated xenograft tumors revealed that the ratio of serum CgA/PSA might provide a better prediction of NED (67). Given that NE-like cells are PSA-low or negative and can secrete $\mathrm{CgA}$, future research should focus on their relationship and the correlation with clinical outcomes.

\section{POTENTIAL IMPACT OF CURRENT TREATMENT MODALITIES ON RADIOTHERAPY-INDUCED NED}

\section{Evaluation of current treatment modalities for locally advanced diseases}

Locally advanced, high-risk, prostate cancer currently poses therapeutic challenges. Currently, the standard management for this group of patients is a combined treatment of RT plus ADT. The rationale for combining RT with ADT was based on the fact that both treatments can kill cancer cells or suppress cancer cell growth, and that the combination may lead to a synergistic effect. Indeed, several phase III clinical studies have demonstrated that RT plus ADT provides a survival benefit, in comparison with either RT or ADT alone $(4,96-99)$. The rationale for adding ADT in the RT setting is that ADT can eliminate androgen-dependent clones, potentiate the tumoricidal effect of RT, and may eradicate micrometastatic disease (96). However, whether ADT can radiosensitize prostate cancer cells is unknown. In fact, in vitro studies using LNCaP cells suggest that androgen depletion did not radiosensitze LNCaP cells in clonogenic assays, though apparent additive effect was observed (100). Given that ADT induces NED in a subpopulation of cancer cells (50-52), it would be necessary to evaluate the impact of this combined therapeutic approach on therapy-induced NED, in comparison to a monotherapy setting (ADT or RT alone). Ideally, developing novel therapeutic agents that not only sensitize prostate cancer cells to RT but also inhibit therapy-induced NED would be ideal and likely initiate a paradigm shift for future management of prostate cancer.

\section{Impact of new treatment modalities on RT-induced NED}

Radiotherapy is one of the main curative modalities for localized prostate cancer. Advances have been made to improve the efficacy of RT in recent years. These include a dose-escalation strategy, a hypofractionation regimen, an incorporation of chemotherapy, and a new RT modality such as high-dose-rate brachytherapy and proton therapy (101-108). Although biological, physical, and clinical rationales clearly support the use of these treatment modalities, their impact on radiation-induced NED remains unstudied. It is worth mentioning that all nine patients enrolled in our pilot clinical study were treated with proton therapy (67). As such, it could be critical to compare the effect of various other RT protocols or modalities on radiation-induced NED. Because FIR-induced NED is completed by a 4-week of irradiation, a dose-escalation strategy over a protracted course likely has a minimal effect on radiationinduced NED. However, other treatment strategies such as an ultra-hypofractionation regimen (e.g., five treatments over 12 weeks) or high-dose-rate brachytherapy (given over 1-2 weeks) may have less extent of radiation-induced NED. Also, proton therapy may have less degree of radiation-induced NED, as it has a higher relative biological effectiveness in comparison to a conventional photon beam. The decrease in radiation-induced NED may, in turn, translate to a clinical benefit with improved treatment outcomes. On a translational research perspective, it would 
be worthwhile to determine whether the observed clinical benefit correlates with the extent of radiation-induced NED. If so, this would provide a biological rationale for exploring different RT regimens or modalities aiming to minimize radiation-induced NED and may also allow for reduction or possible elimination of the use of adjuvant $\mathrm{ADT}$ in RT setting.

\section{CONCLUSION}

Although NED has been a well-recognized phenotypic change in prostate cancer, its impact on prostate cancer progression and therapeutic responses has only recently gained significant attention. Several studies have provided compelling evidence that preexisting NED confers resistance to treatments such as RT. However, the impact of therapy-induced NED on disease progression and treatment failures has not been rigorously studied. Using FIRinduced NED as a model system, we have provided evidence that targeting FIR-induced NED is an effective radiosensitizing approach. Future research should be directed at understanding the molecular mechanisms by which FIR induces NED and confers acquired radioresistance as well as tumor recurrence. With the use of appropriate animal models, implementation of new technologies as well as methodologies to diagnose RT-induced NED and better understanding of the biological effect of novel treatment modalities, we hope that a better RT strategy will be developed and implemented in clinical practice in the future.

\section{ACKNOWLEDGMENTS}

We would like to thank many collaborators who have contributed to the study of radiation-induced neuroendocrine differentiation in prostate cancer cells in the $\mathrm{Hu}$ lab. The prostate cancer research projects in the Hu lab have been supported by grants from U.S. Army Medical Research Acquisition Activity, Prostate Cancer Research Program (PC073098, PC11190, and PC120512), Purdue University Center for Cancer Research Small Grants Program, and the Indiana Clinical and Translational Science Institute funded, in part, by RR-25761 from the National Institutes of Health, National Center for Research Resources, Clinical and Translational Sciences Award. DNA sequencing was conducted in the Purdue University Center for Cancer Research Genomic Core Facility Supported by NCI CCSG CA23168 to Purdue University Center for Cancer Research.

\section{REFERENCES}

1. Siegel R, Desantis C, Virgo K, Stein K, Mariotto A, Smith T, et al. Cancer treatment and survivorship statistics, 2012. CA Cancer J Clin (2012) 62(4):220-41. doi:10.3322/caac. 21149

2. D'Amico AV. Risk-based management of prostate cancer. N Engl J Med (2011) 365(2):169-71. doi:10.1056/NEJMe1103829

3. D’Amico AV, Whittington R, Malkowicz SB, Schultz D, Blank K, Broderick GA, et al. Biochemical outcome after radical prostatectomy, external beam radiation therapy, or interstitial radiation therapy for clinically localized prostate cancer. JAMA (1998) 280(11):969-74. doi:10.1001/jama.280.11.969

4. Boorjian SA, Karnes RJ, Viterbo R, Rangel LJ, Bergstralh EJ, Horwitz EM, et al. Long-term survival after radical prostatectomy versus external-beam radiotherapy for patients with high-risk prostate cancer. Cancer (2011) 117(13):2883-91. doi:10.1002/cncr.25900

5. Kuban DA, Thames HD, Levy LB, Horwitz EM, Kupelian PA, Martinez AA, et al. Long-term multi-institutional analysis of stage T1-T2 prostate cancer treated with radiotherapy in the PSA era. Int J Radiat Oncol Biol Phys (2003) 57(4):915-28. doi:10.1016/S0360-3016(03)00632-1
6. Zietman AL, DeSilvio ML, Slater JD, Rossi CJ Jr, Miller DW, Adams JA, et al. Comparison of conventional-dose vs high-dose conformal radiation therapy in clinically localized adenocarcinoma of the prostate: a randomized controlled trial. JAMA (2005) 294(10):1233-9. doi:10.1001/jama.294.10.1233

7. D'Amico AV, Chen MH, Renshaw AA, Loffredo B, Kantoff PW. Risk of prostate cancer recurrence in men treated with radiation alone or in conjunction with combined or less than combined androgen suppression therapy. J Clin Oncol (2008) 26(18):2979-83. doi:10.1200/JCO.2007.15.9699

8. Jemal A, Siegel R, Xu J, Ward E. Cancer statistics, 2010. CA Cancer J Clin (2010) 60(5):277-300. doi:10.3322/caac.20073

9. Harrington K, Jankowska P, Hingorani M. Molecular biology for the radiation oncologist: the 5Rs of radiobiology meet the hallmarks of cancer. Clin Oncol ( $R$ Coll Radiol) (2007) 19(8):561-71. doi:10.1016/j.clon.2007.04.009

10. Vashchenko N, Abrahamsson PA. Neuroendocrine differentiation in prostate cancer: implications for new treatment modalities. Eur Urol (2005) 47(2):147-55. doi:10.1016/j.eururo.2004.09.007

11. Bonkhoff H. Neuroendocrine differentiation in human prostate cancer. Morphogenesis, proliferation and androgen receptor status. Ann Oncol (2001) 12(Suppl 2):S141-4. doi:10.1023/A:1012454926267

12. di Sant'Agnese PA. Neuroendocrine differentiation in prostatic carcinoma: an update on recent developments. Ann Oncol (2001) 12(Suppl 2):S135-40. doi:10.1023/A:1012402909428

13. Mosca A, Berruti A, Russo L, Torta M, Dogliotti L. The neuroendocrine phenotype in prostate cancer: basic and clinical aspects. J Endocrinol Invest (2005) 28(11 Suppl):141-5.

14. Nelson EC, Cambio AJ, Yang JC, Ok JH, Lara PN Jr, Evans CP. Clinical implications of neuroendocrine differentiation in prostate cancer. Prostate Cancer Prostatic Dis (2007) 10(1):6-14. doi:10.1038/sj.pcan.4500922

15. Yuan TC, Veeramani S, Lin MF. Neuroendocrine-like prostate cancer cells: neuroendocrine transdifferentiation of prostate adenocarcinoma cells. Endocr Relat Cancer (2007) 14(3):531-47. doi:10.1677/ERC-07-0061

16. Cindolo L, Cantile M, Vacherot F, Terry S, de la Taille A. Neuroendocrine differentiation in prostate cancer: from lab to bedside. Urol Int (2007) 79(4):287-96. doi:10.1159/000109711

17. Conteduca V, Aieta M, Amadori D, De Giorgi U. Neuroendocrine differentiation in prostate cancer: current and emerging therapy strategies. Crit Rev Oncol Hematol (2014) 92(1):11-24. doi:10.1016/j.critrevonc.2014.05.008

18. Huang J, Wu C, di Sant'Agnese PA, Yao JL, Cheng L, Na Y. Function and molecular mechanisms of neuroendocrine cells in prostate cancer. Anal Quant Cytol Histol (2007) 29(3):128-38.

19. Daneshmand S, Quek ML, Pinski J. Neuroendocrine differentiation in prostate cancer. Cancer Ther (2005) 3:383-96.

20. Amorino GP, Parsons SJ. Neuroendocrine cells in prostate cancer. Crit Rev Eukaryot Gene Expr (2004) 14(4):287-300. doi:10.1615/ CritRevEukarGeneExpr.v14.i4.40

21. Lilleby W, Paus E, Skovlund E, Fossa SD. Prognostic value of neuroendocrine serum markers and PSA in irradiated patients with pN0 localized prostate cancer. Prostate (2001) 46(2):126-33. doi:10.1002/1097-0045(20010201)46: $2<126:$ :AID-PROS1016>3.3.CO;2-Z

22. Krauss DJ, Hayek S, Amin M, Ye H, Kestin LL, Zadora S, et al. Prognostic significance of neuroendocrine differentiation in patients with Gleason score 8-10 prostate cancer treated with primary radiotherapy. Int J Radiat Oncol Biol Phys (2011) 81(3):e119-25. doi:10.1016/j.ijrobp.2010.12.064

23. Berruti A, Mosca A, Tucci M, Terrone C, Torta M, Tarabuzzi R, et al. Independent prognostic role of circulating chromogranin A in prostate cancer patients with hormone-refractory disease. Endocr Relat Cancer (2005) 12(1):109-17. doi:10.1677/erc. 1.00876

24. Khan MO, Ather MH. Chromogranin A - serum marker for prostate cancer. J Pak Med Assoc (2011) 61(1):108-11.

25. Komiya A, Suzuki H, Imamoto T, Kamiya N, Nihei N, Naya Y, et al. Neuroendocrine differentiation in the progression of prostate cancer. Int J Urol (2009) 16(1):37-44. doi:10.1111/j.1442-2042.2008.02175.x

26. Quek ML, Daneshmand S, Rodrigo S, Cai J, Dorff TB, Groshen S, et al. Prognostic significance of neuroendocrine expression in lymph node-positive prostate cancer. Urology (2006) 67(6):1247-52. doi:10.1016/j.urology.2005.12.009

27. Taplin ME, George DJ, Halabi S, Sanford B, Febbo PG, Hennessy KT, et al. Prognostic significance of plasma chromogranin a levels in patients with hormonerefractory prostate cancer treated in cancer and leukemia group B 9480 study. Urology (2005) 66(2):386-91. doi:10.1016/j.urology.2005.03.040 
28. Krauss DJ, Amin M, Stone B, Ye H, Hayek S, Cotant M, et al. Chromogranin A staining as a prognostic variable in newly diagnosed Gleason score 7-10 prostate cancer treated with definitive radiotherapy. Prostate (2014) 74(5):520-7. doi:10.1002/pros.22771

29. Xing N, Qian J, Bostwick D, Bergstralh E, Young CY. Neuroendocrine cells in human prostate over-express the anti-apoptosis protein survivin. Prostate (2001) 48(1):7-15. doi:10.1002/pros.1076

30. Gong J, Lee J, Akio H, Schlegel PN, Shen R. Attenuation of apoptosis by chromogranin A-induced Akt and survivin pathways in prostate cancer cells. Endocrinology (2007) 148(9):4489-99. doi:10.1210/en.2006-1748

31. Segal NH, Cohen RJ, Haffejee Z, Savage N. BCL-2 proto-oncogene expression in prostate cancer and its relationship to the prostatic neuroendocrine cell. Arch Pathol Lab Med (1994) 118(6):616-8.

32. Vanoverberghe K, Vanden Abeele F, Mariot P, Lepage G, Roudbaraki M, Bonnal JL, et al. Ca2+ homeostasis and apoptotic resistance of neuroendocrinedifferentiated prostate cancer cells. Cell Death Differ (2004) 11(3):321-30. doi:10.1038/sj.cdd.4401375

33. Cox ME, Deeble PD, Lakhani S, Parsons SJ. Acquisition of neuroendocrine characteristics by prostate tumor cells is reversible: implications for prostate cancer progression. Cancer Res (1999) 59(15):3821-30.

34. Dayon A, Brizuela L, Martin C, Mazerolles C, Pirot N, Doumerc N, et al. Sphingosine kinase- 1 is central to androgen-regulated prostate cancer growth and survival. PLoS One (2009) 4(11):e8048. doi:10.1371/journal.pone.0008048

35. Zelivianski S, Verni M, Moore C, Kondrikov D, Taylor R, Lin MF. Multipathways for transdifferentiation of human prostate cancer cells into neuroendocrinelike phenotype. Biochim Biophys Acta (2001) 1539(1-2):28-43. doi:10.1016/ S0167-4889(01)00087-8

36. Deeble PD, Murphy DJ, Parsons SJ, Cox ME. Interleukin-6- and cyclic AMP-mediated signaling potentiates neuroendocrine differentiation of $\mathrm{LNCaP}$ prostate tumor cells. Mol Cell Biol (2001) 21(24):8471-82. doi:10.1128/MCB. 21.24.8471-8482.2001

37. Merkle D, Hoffmann R. Roles of cAMP and cAMP-dependent protein kinase in the progression of prostate cancer: cross-talk with the androgen receptor. Cell Signal (2011) 23(3):507-15. doi:10.1016/j.cellsig.2010.08.017

38. Deeble PD, Cox ME, Frierson HF Jr, Sikes RA, Palmer JB, Davidson RJ, et al. Androgen-independent growth and tumorigenesis of prostate cancer cells are enhanced by the presence of PKA-differentiated neuroendocrine cells. Cancer Res (2007) 67(8):3663-72. doi:10.1158/0008-5472.CAN-06-2616

39. Bang YJ, Pirnia F, Fang WG, Kang WK, Sartor O, Whitesell L, et al. Terminal neuroendocrine differentiation of human prostate carcinoma cells in response to increased intracellular cyclic AMP. Proc Natl Acad Sci U S A (1994) 91(12):5330-4. doi:10.1073/pnas.91.12.5330

40. Park MH, Lee HS, Lee CS, You ST, Kim DJ, Park BH, et al. p21-Activated kinase 4 promotes prostate cancer progression through CREB. Oncogene (2013) 32(19):2475-82. doi:10.1038/onc.2012.255

41. Cox ME, Deeble PD, Bissonette EA, Parsons SJ. Activated 3',5'-cyclic AMPdependent protein kinase is sufficient to induce neuroendocrine-like differentiation of the LNCaP prostate tumor cell line. J Biol Chem (2000) 275(18):13812-8. doi:10.1074/jbc.275.18.13812

42. Spiotto MT, Chung TD. STAT3 mediates IL-6-induced neuroendocrine differentiation in prostate cancer cells. Prostate (2000) 42(3):186-95. doi:10.1002/ (SICI) 1097-0045(20000215)42:3<186::AID-PROS4>3.0.CO;2-E

43. Lee SO, Chun JY, Nadiminty N, Lou W, Gao AC. Interleukin-6 undergoes transition from growth inhibitor associated with neuroendocrine differentiation to stimulator accompanied by androgen receptor activation during LNCaP prostate cancer cell progression. Prostate (2007) 67(7):764-73. doi:10.1002/pros.20553

44. Wang Q, Horiatis D, Pinski J. Inhibitory effect of IL-6-induced neuroendocrine cells on prostate cancer cell proliferation. Prostate (2004) 61(3):253-9. doi:10.1002/pros.20106

45. Wang Q, Horiatis D, Pinski J. Interleukin-6 inhibits the growth of prostate cancer xenografts in mice by the process of neuroendocrine differentiation. Int J Cancer (2004) 111(4):508-13. doi:10.1002/ijc.20286

46. Qiu Y, Robinson D, Pretlow TG, Kung HJ. Etk/Bmx, a tyrosine kinase with a pleckstrin-homology domain, is an effector of phosphatidylinositol 3'kinase and is involved in interleukin 6-induced neuroendocrine differentiation of prostate cancer cells. Proc Natl Acad Sci U S A (1998) 95(7):3644-9. doi:10.1073/pnas.95.7.3644
47. Martin-Orozco RM, Almaraz-Pro C, Rodriguez-Ubreva FJ, Cortes MA, Ropero $\mathrm{S}$, Colomer R, et al. EGF prevents the neuroendocrine differentiation of LNCaP cells induced by serum deprivation: the modulator role of PI3K/Akt. Neoplasia (2007) 9(8):614-24. doi:10.1593/neo.07337

48. Cortes MA, Cariaga-Martinez AE, Lobo MV, Martin Orozco RM, Motino O, Rodriguez-Ubreva FJ, et al. EGF promotes neuroendocrine-like differentiation of prostate cancer cells in the presence of LY294002 through increased ErbB2 expression independent of the phosphatidylinositol 3-kinase-AKT pathway. Carcinogenesis (2012) 33(6):1169-77. doi:10.1093/carcin/bgs139

49. Humez S, Monet M, Legrand G, Lepage G, Delcourt P, Prevarskaya N. Epidermal growth factor-induced neuroendocrine differentiation and apoptotic resistance of androgen-independent human prostate cancer cells. Endocr Relat Cancer (2006) 13(1):181-95. doi:10.1677/erc.1.01079

50. Sciarra A, Monti S, Gentile V, Mariotti G, Cardi A, Voria G, et al. Variation in chromogranin A serum levels during intermittent versus continuous androgen deprivation therapy for prostate adenocarcinoma. Prostate (2003) 55(3):168-79. doi:10.1002/pros.10222

51. Berruti A, Mosca A, Porpiglia F, Bollito E, Tucci M, Vana F, et al. Chromogranin A expression in patients with hormone naive prostate cancer predicts the development of hormone refractory disease. J Urol (2007) 178(3 Pt 1):838-43. doi:10.1016/j.juro.2007.05.018

52. Hirano D, Okada Y, Minei S, Takimoto Y, Nemoto N. Neuroendocrine differentiation in hormone refractory prostate cancer following androgen deprivation therapy. Eur Urol (2004) 45(5):586-92. doi:10.1016/j.eururo.2003.11.032

53. Sarkar D, Singh SK, Mandal AK, Agarwal MM, Mete UK, Kumar S, et al. Plasma chromogranin A: clinical implications in patients with castrate resistant prostate cancer receiving docetaxel chemotherapy. Cancer Biomark (2010) 8(2):81-7. doi:10.3233/CBM-2011-0198

54. Burgio SL, Conteduca V, Menna C, Carretta E, Rossi L, Bianchi E, et al. Chromogranin A predicts outcome in prostate cancer patients treated with abiraterone. Endocr Relat Cancer (2014) 21(3):487-93. doi:10.1530/ERC-14-0071

55. Conteduca V, Burgio SL, Menna C, Carretta E, Rossi L, Bianchi E, et al. Chromogranin A is a potential prognostic marker in prostate cancer patients treated with enzalutamide. Prostate (2014) 74(16):1691-6. doi:10.1002/pros.22890

56. Zhang XQ, Kondrikov D, Yuan TC, Lin FF, Hansen J, Lin MF. Receptor protein tyrosine phosphatase alpha signaling is involved in androgen depletioninduced neuroendocrine differentiation of androgen-sensitive LNCaP human prostate cancer cells. Oncogene (2003) 22(43):6704-16. doi:10.1038/sj.onc. 1206764

57. Uysal-Onganer P, Kawano Y, Caro M, Walker MM, Diez S, Darrington RS, et al. Wnt-11 promotes neuroendocrine-like differentiation, survival and migration of prostate cancer cells. Mol Cancer (2010) 9:55. doi:10.1186/1476-4598-9-55

58. Yuan TC, Veeramani S, Lin FF, Kondrikou D, Zelivianski S, Igawa T, et al. Androgen deprivation induces human prostate epithelial neuroendocrine differentiation of androgen-sensitive LNCaP cells. Endocr Relat Cancer (2006) 13(1):151-67. doi:10.1677/erc.1.01043

59. Berenguer C, Boudouresque F, Dussert C, Daniel L, Muracciole X, Grino M, et al. Adrenomedullin, an autocrine/paracrine factor induced by androgen withdrawal, stimulates 'neuroendocrine phenotype' in LNCaP prostate tumor cells. Oncogene (2008) 27(4):506-18. doi:10.1038/sj.onc. 1210656

60. Jongsma J, Oomen MH, Noordzij MA, Van Weerden WM, Martens GJ, van der Kwast TH, et al. Different profiles of neuroendocrine cell differentiation evolve in the PC-310 human prostate cancer model during long-term androgen deprivation. Prostate (2002) 50(4):203-15. doi:10.1002/pros.10049

61. Huss WJ, Gregory CW, Smith GJ. Neuroendocrine cell differentiation in the CWR22 human prostate cancer xenograft: association with tumor cell proliferation prior to recurrence. Prostate (2004) 60(2):91-7. doi:10.1002/pros.20032

62. Jongsma J, Oomen MH, Noordzij MA, Van Weerden WM, Martens GJ, van der Kwast TH, et al. Androgen deprivation of the PC-310 [correction of prohormone convertase-310] human prostate cancer model system induces neuroendocrine differentiation. Cancer Res (2000) 60(3):741-8.

63. Jongsma J, Oomen MH, Noordzij MA, Van Weerden WM, Martens GJ, van der Kwast TH, et al. Kinetics of neuroendocrine differentiation in an androgen-dependent human prostate xenograft model. Am J Pathol (1999) 154(2):543-51. doi:10.1016/S0002-9440(10)65300-X

64. Noordzij MA, van Weerden WM, de Ridder CM, van der Kwast TH, Schroder FH, van Steenbrugge GJ. Neuroendocrine differentiation in human prostatic tumor models. Am J Pathol (1996) 149(3):859-71. 
65. Lin D, Wyatt AW, Xue H, Wang Y, Dong X, Haegert A, et al. High fidelity patientderived xenografts for accelerating prostate cancer discovery and drug development. Cancer Res (2014) 74(4):1272-83. doi:10.1158/0008-5472.CAN-132921-T

66. Deng X, Liu H, Huang J, Cheng L, Keller ET, Parsons SJ, et al. Ionizing radiation induces prostate cancer neuroendocrine differentiation through interplay of CREB and ATF2: implications for disease progression. Cancer Res (2008) 68(23):9663-70. doi:10.1158/0008-5472.CAN-08-2229

67. Deng X, Elzey BD, Poulson JM, Morrison WB, Ko SC, Hahn NM, et al. Ionizing radiation induces neuroendocrine differentiation of prostate cancer cells in vitro, in vivo and in prostate cancer patients. Am J Cancer Res (2011) 1(7):834-44.

68. Palapattu GS, Wu C, Silvers CR, Martin HB, Williams K, Salamone L, et al. Selective expression of CD44, a putative prostate cancer stem cell marker, in neuroendocrine tumor cells of human prostate cancer. Prostate (2009) 69(7):787-98. doi:10.1002/pros.20928

69. Qin J, Liu X, Laffin B, Chen X, Choy G, Jeter CR, et al. The PSA(-/lo) prostate cancer cell population harbors self-renewing long-term tumor-propagating cells that resist castration. Cell Stem Cell (2012) 10(5):556-69. doi:10.1016/j. stem.2012.03.009

70. Kyjacova L, Hubackova S, Krejcikova K, Strauss R, Hanzlikova H, Dzijak $\mathrm{R}$, et al. Radiotherapy-induced plasticity of prostate cancer mobilizes stemlike non-adherent, Erk signaling-dependent cells. Cell Death Differ (2014). doi:10.1038/cdd.2014.97

71. McKeithen D, Graham T, Chung LW, Odero-Marah V. Snail transcription factor regulates neuroendocrine differentiation in LNCaP prostate cancer cells. Prostate (2010) 70(9):982-92. doi:10.1002/pros.21132

72. Danza G, Di Serio C, Rosati F, Lonetto G, Sturli N, Kacer D, et al. Notch signaling modulates hypoxia-induced neuroendocrine differentiation of human prostate cancer cells. Mol Cancer Res (2012) 10(2):230-8. doi:10.1158/15417786.MCR-11-0296

73. Luo Y, Lan L, Jiang YG, Zhao JH, Li MC, Wei NB, et al. Epithelial-mesenchymal transition and migration of prostate cancer stem cells is driven by cancerassociated fibroblasts in an HIF-lalpha/beta-catenin-dependent pathway. Mol Cells (2013) 36(2):138-44. doi:10.1007/s10059-013-0096-8

74. Marhold M, Tomasich E, El-Gazzar A, Heller G, Spittler A, Horvat R, et al. HIFlalpha regulates mTOR signaling and viability of prostate cancer stem cells. $\mathrm{Mol}$ Cancer Res (2014) 13(3):556-64. doi:10.1158/1541-7786.MCR-14-0153-T

75. Bhoumik A, Ronai Z. ATF2: a transcription factor that elicits oncogenic or tumor suppressor activities. Cell Cycle (2008) 7(15):2341-5. doi:10.4161/ cc. 6388

76. Lau E, Ronai ZA. ATF2 - at the crossroad of nuclear and cytosolic functions. J Cell Sci (2012) 125(Pt 12):2815-24. doi:10.1242/jcs.095000

77. Liu H, Deng X, Shyu YJ, Li JJ, Taparowsky EJ, Hu CD. Mutual regulation of cJun and ATF2 by transcriptional activation and subcellular localization. EMBO $J$ (2006) 25(5):1058-69. doi:10.1038/sj.emboj.7601183

78. Hsu CC, Hu CD. Critical role of N-terminal end-localized nuclear export signal in regulation of activating transcription factor 2 (ATF2) subcellular localization and transcriptional activity. J Biol Chem (2012) 287(11):8621-32. doi:10.1074/jbc.M111.294272

79. Canaff L, Bevan S, Wheeler DG, Mouland AJ, Rehfuss RP, White JH, et al. Analysis of molecular mechanisms controlling neuroendocrine cell specific transcription of the chromogranin A gene. Endocrinology (1998) 139(3):1184-96. doi:10.1210/en.139.3.1184

80. Shaywitz AJ, Greenberg ME. CREB: a stimulus-induced transcription factor activated by a diverse array of extracellular signals. Annu Rev Biochem (1999) 68:821-61. doi:10.1146/annurev.biochem.68.1.821

81. Suarez CD, Deng X, Hu CD. Targeting CREB inhibits radiation-induced neuroendocrine differentiation and increases radiation-induced cell death in prostate cancer cells. Am J Cancer Res (2014) 4(6):850-61.

82. Ahn S, Olive M, Aggarwal S, Krylov D, Ginty DD, Vinson C. A dominant-negative inhibitor of CREB reveals that it is a general mediator of stimulus-dependent transcription of c-fos. Mol Cell Biol (1998) 18(2):967-77.

83. Impey S, McCorkle SR, Cha-Molstad H, Dwyer JM, Yochum GS, Boss JM, et al. Defining the CREB regulon: a genome-wide analysis of transcription factor regulatory regions. Cell (2004) 119(7):1041-54. doi:10.1016/j.cell.2004. 10.032
84. Xiao X, Li BX, Mitton B, Ikeda A, Sakamoto KM. Targeting CREB for cancer therapy: friend or foe. Curr Cancer Drug Targets (2010) 10(4):384-91. doi:10.2174/156800910791208535

85. Groner B, Weiss A. Targeting survivin in cancer: novel drug development approaches. BioDrugs (2014) 28(1):27-39. doi:10.1007/s40259-013-0058-x

86. Jin RJ, Wang Y, Masumori N, Ishii K, Tsukamoto T, Shappell SB, et al. NE10 neuroendocrine cancer promotes the LNCaP xenograft growth in castrated mice. Cancer Res (2004) 64(15):5489-95. doi:10.1158/0008-5472.CAN03-3117

87. Amorino GP, Deeble PD, Parsons SJ. Neurotensin stimulates mitogenesis of prostate cancer cells through a novel c-Src/Stat5b pathway. Oncogene (2007) 26(5):745-56. doi:10.1038/sj.onc.1209814

88. Ittmann M, Huang J, Radaelli E, Martin P, Signoretti S, Sullivan R, et al. Animal models of human prostate cancer: the consensus report of the New York meeting of the mouse models of human cancers consortium prostate pathology committee. Cancer Res (2013) 73(9):2718-36. doi:10.1158/0008-5472.CAN$12-4213$

89. Greenberg NM, DeMayo F, Finegold MJ, Medina D, Tilley WD, Aspinall JO, et al. Prostate cancer in a transgenic mouse. Proc Natl Acad Sci U S A (1995) 92(8):3439-43. doi:10.1073/pnas.92.8.3439

90. Qi J, Nakayama K, Cardiff RD, Borowsky AD, Kaul K, Williams R, et al. Siah2-dependent concerted activity of HIF and FoxA2 regulates formation of neuroendocrine phenotype and neuroendocrine prostate tumors. Cancer Cell (2010) 18(1):23-38. doi:10.1016/j.ccr.2010.05.024

91. Mulholland DJ, Tran LM, Li Y, Cai H, Morim A, Wang S, et al. Cell autonomous role of PTEN in regulating castration-resistant prostate cancer growth. Cancer Cell (2011) 19(6):792-804. doi:10.1016/j.ccr.2011.05.006

92. Wang S, Gao J, Lei Q, Rozengurt N, Pritchard C, Jiao J, et al. Prostatespecific deletion of the murine Pten tumor suppressor gene leads to metastatic prostate cancer. Cancer Cell (2003) 4(3):209-21. doi:10.1016/S1535-6108(03) 00215-0

93. Angelsen A, Syversen U, Haugen OA, Stridsberg M, Mjolnerod OK, Waldum HL. Neuroendocrine differentiation in carcinomas of the prostate: do neuroendocrine serum markers reflect immunohistochemical findings? Prostate (1997) 30(1):1-6. doi:10.1002/(SICI) 1097-0045(19970101)30:1<1: :AID-PROS1>3.3.CO;2-B

94. Berruti A, Dogliotti L, Mosca A, Bellina M, Mari M, Torta M, et al. Circulating neuroendocrine markers in patients with prostate carcinoma. Cancer (2000) 88(11):2590-7. doi:10.1002/1097-0142(20000601)88:11<2590::AIDCNCR23>3.0.CO;2-D

95. Sasaki T, Komiya A, Suzuki H, Shimbo M, Ueda T, Akakura K, et al. Changes in chromogranin a serum levels during endocrine therapy in metastatic prostate cancer patients. Eur Urol (2005) 48(2):224-9. doi:10.1016/j.eururo. 2005.03.017

96. D'Amico A. Radiation and hormonal therapy for locally advanced and clinically localized prostate cancer. Urology (2001) 58(2 Suppl 1):78-82. doi:10. 1016/S0090-4295(01)01246-8

97. Pollack A, Kuban DA, Zagars GK. Impact of androgen deprivation therapy on survival in men treated with radiation for prostate cancer. Urology (2002) 60(3 Suppl 1):22-30. doi:10.1016/S0090-4295(02)01564-9

98. D'Amico AV. Radiation and hormonal therapy for locally advanced and clinically localized prostate cancer. Urology (2002) 60(3 Suppl 1):32-7. doi:10.1016/ S0090-4295(02)01566-2

99. Lee WR. The role of androgen deprivation therapy combined with prostate brachytherapy. Urology (2002) 60(3 Suppl 1):39-44. doi:10.1016/S00904295(02)01568-6

100. Pollack A, Salem N, Ashoori F, Hachem P, Sangha M, von Eschenbach AC, et al. Lack of prostate cancer radiosensitization by androgen deprivation. Int J Radiat Oncol Biol Phys (2001) 51(4):1002-7. doi:10.1016/S0360-3016(01)01750-3

101. Pearlstein KA, Chen RC. Comparing dosimetric, morbidity, quality of life, and cancer control outcomes after 3D conformal, intensity-modulated, and proton radiation therapy for prostate cancer. Semin Radiat Oncol (2013) 23(3):182-90. doi:10.1016/j.semradonc.2013.01.004

102. Pugh TJ, Nguyen BN, Kanke JE, Johnson JL, Hoffman KE. Radiation therapy modalities in prostate cancer. J Natl Compr Canc Netw (2013) 11(4):414-21.

103. Mishra MV, Showalter TN. Pushing the limits of radiation therapy for prostate cancer: where do we go next? Semin Oncol (2013) 40(3):297-307. doi:10.1053/j.seminoncol.2013.04.005 
104. Zaorsky NG, Harrison AS, Trabulsi EJ, Gomella LG, Showalter TN, Hurwitz MD, et al. Evolution of advanced technologies in prostate cancer radiotherapy. Nat Rev Urol (2013) 10(10):565-79. doi:10.1038/nrurol. 2013.185

105. Koontz BF, Bossi A, Cozzarini C, Wiegel T, D’Amico A. A systematic review of hypofractionation for primary management of prostate cancer. Eur Urol (2014). doi:10.1016/j.eururo.2014.08.009

106. Morton GC. High-dose-rate brachytherapy boost for prostate cancer: rationale and technique. J Contemp Brachytherapy (2014) 6(3):323-30. doi:10.5114/jcb. 2014.45759

107. Gray PJ, Efstathiou JA. Proton beam radiation therapy for prostate canceris the hype (and the cost) justified? Curr Urol Rep (2013) 14(3):199-208. doi:10.1007/s11934-013-0320-2

108. Efstathiou JA, Gray PJ, Zietman AL. Proton beam therapy and localised prostate cancer: current status and controversies. Br J Cancer (2013) 108(6):1225-30. doi:10.1038/bjc. 2013.100
Conflict of Interest Statement: The authors declare that the research was conducted in the absence of any commercial or financial relationships that could be construed as a potential conflict of interest.

Received: 14 December 2014; accepted: 26 March 2015; published online: 14 April 2015. Citation: Hu C-D, Choo R and Huang J (2015) Neuroendocrine differentiation in prostate cancer: a mechanism of radioresistance and treatment failure. Front. Oncol. 5:90. doi: 10.3389/fonc.2015.00090

This article was submitted to Genitourinary Oncology, a section of the journal Frontiers in Oncology.

Copyright (c) $2015 \mathrm{Hu}$, Choo and Huang. This is an open-access article distributed under the terms of the Creative Commons Attribution License (CC BY). The use, distribution or reproduction in other forums is permitted, provided the original author(s) or licensor are credited and that the original publication in this journal is cited, in accordance with accepted academic practice. No use, distribution or reproduction is permitted which does not comply with these terms. 